\title{
Correction to: New surface microstructure of mono-si wafer textured using wet chemical solutions for solar cell
}

\author{
Xiao Tong Gong ${ }^{1} \cdot$ Shi Meng Feng ${ }^{1} \cdot$ Gang Lei $^{2} \cdot$ Meng Qi Shi $^{2}$
}

Published online: 13 June 2019

○) Springer-Verlag GmbH Germany, part of Springer Nature 2019

Correction to: Applied Physics A (2019) 125:265 https://doi.org/10.1007/s00339-019-2565-1

Dear readers,

Unfortunately the addition (revised paper (2)) was published in the title of this article.

This addition was not deleted by mistake during the typesetting process. The correct title of the article should therefore read as follows:

New surface microstructure of mono-si wafer textured using wet chemical solutions for solar cell

We apologize for this error.

The original article has been corrected.

The original article can be found online at https://doi.org/10.1007/ s00339-019-2565-1.

Shi Meng Feng

smfeng@sjtu.edu.cn

1 School of Physics and Astronomy, Shanghai Jiao Tong University, Shanghai, People's Republic of China

2 Shanghai Institute of Space Power and Sources, Shanghai, People's Republic of China
Publisher's Note Springer Nature remains neutral with regard to jurisdictional claims in published maps and institutional affiliations 